\title{
The transport performance evaluation system building of logistics enterprises
}

\author{
Xueli Wang ${ }^{1}$, Yu Chen², Li Zhang ${ }^{3}$ \\ 1,2Shijiazhuang Institute of Railway Technology (China) \\ ${ }^{3}$ National Library of China (China) \\ 'fairyfox27@163.com,28254055@qq.com,33zhangli@nlc.gov.cn
}

Received: March 2013

Accepted: May 2013

\section{Abstrac:}

Purpose The modern logistics has a significant role in today's society, logistics cost accounts for $35 \%$ to $50 \%$ of the total logistics costs, so it has great significance to improve the transport performance of logistics enterprises.

Design/methoddogy/approadr. The authors selected the transportation performance evaluation index of logistics enterprise, with the aid of the fuzzy theory and analytic hierarchy process (AHP), adopted the combining method of quantitative and qualitative analysis, constructed the transport performance evaluation system of logistics enterprises.

Findings: Through the model analysis, we know that the choice of logistics enterprises transportation performance evaluation index system is in the condition of relatively high, which has certain guiding significance to improve transport efficiency and reduce transportation cost for the logistics enterprise.

Research limitations/implications: It has great significance to improve the transport performance of the logistics enterprises. But because of the experts' subjective factors, the selected indicators of the text can not accurately quantify.

Practical implications: It has important practical significance to promote the development of modern logistics enterprises and save the social cost. 
Originality/value Current research methods of transport performance mainly include the PDCA cycle model, key performance indicators (KPI), principal component analysis method and etc. The authors adopted the combining method of the fuzzy theory and analytic hierarchy process (AHP) research on transport performance problems.

Keywords: transportation performance, the fuzzy theory, analytic hierarchy process (AHP)

\section{Introduction}

Transportation occupies very important position in the modern logistics industry, transport costs are also important in the proportion of the whole logistics system, according to relevant statistics show that: transport costs account for about $35 \%$ to $50 \%$ of the total logistics cost, and about $4 \%$ to $10 \%$ of commodity prices. Therefore, it's very important for logistics enterprises to save the transportation cost, and it's also very significant for the society as a whole logistics total cost saving. With logistics cost minimization goal, it is a big problem for us how to choose and evaluate logistics service providers scientifically and correctly. Transportation performance evaluation is important methods for consideration the logistics service providers (Yuan \& Meng, 2013).

Transportation performance evaluation refers to the performance evaluation of transportation activities or transportation process. It is generally in accordance with the uniform evaluation criteria, adopting certain index system, according to certain procedures, using qualitative and quantitative methods, making the comprehensive judgment to a certain period of time transport activity or process effectiveness and efficiency. Transportation performance evaluation is main steps for the logistics enterprises and other related enterprises. With the help of transportation performance evaluation of logistics enterprises can optimize the process, improve the economic benefit (Li, Wang \& Han, 2009).

\section{The transport performance evaluation system building of logistics enterprises}

Because vital role of transportation in the modern logistics industry, in recent years, the study of logistics transportation has increasingly become one of hot research topic in regional development both at home and abroad, there are PDCA cycle model, key performance indicators (KPI) and benchmarking method, principal component analysis method, etc (Wei, 2006). With the aid of fuzzy theory and AHP method, the authors constructed the performance evaluation of logistics enterprise transport model, and applied this model to evaluate logistics enterprise transport system, further promoted the management work of the logistics service providers to be standard and procedure (Zhang, 2007).

Logistics enterprise transportation evaluation concerns many indicators, and each index involves many relevant factors. In these factors, some can use quantity exact expression, some 
difficult to quantify the exact expression, only can qualitative expression. Thus the AHP method and fuzzy theory can be combined, quantitative indexes and qualitative indexes will be together for multi-grade fuzzy comprehensive evaluation.

AHP is a method using which qualitative problem can be translated into a quantitative analysis, the basic idea is: first, build hierarchical analysis structure model, then through comparison between each two factors of each layer, comparative judgment matrix is constructed. Judgment matrix means according to the factors above itself, the factors of this level and related factors compared relative importance. Judgment matrix is the basic information of the $\mathrm{AHP}$, is also an important basis for the calculation of relative importance. Eventually the qualitative analysis and comprehensive evaluation were attributed to the weights of relative importance of the lower layer relative its upper level. Using mathematical expression is eigenvalue and eigenvector problem (Nie, Zhang \& Yang, 2005).

\subsection{Establish effect evaluation sets $v$}

Evaluation sets is that evaluators make the set of qualitative description according to evaluation objects. In the article, The transport performance evaluation of logistics enterprise is divided into 5 levels, The corresponding evaluation set $V=\left\{v_{1}, v_{2}, v_{3}, v_{4}, v_{5}\right\}=\{$ absolutely high, very high, higher, slightly high, generally high\}.

\subsection{Establish effect evaluation index collection $U$}

The performance evaluation of logistics transport enterprise set about service quality, service cost, market capacity, information capacity four aspects. Detailed is in the following table.

\begin{tabular}{|c|c|c|}
\hline $\mathbf{u}$ & The first level index $U_{i}$ & The second level index $\mathbf{U}_{\mathrm{ij}}$ \\
\hline \multirow{4}{*}{$\begin{array}{l}\text { Transport performance } \\
\text { evaluation index } \\
\text { system of logistics } \\
\text { enterprise }\end{array}$} & $\begin{array}{l}\text { Service quality } \\
\text { performance indicators } U_{1}\end{array}$ & $\begin{array}{l}\mathrm{U}_{11} \text { : correct order processing rate } \\
\mathrm{U}_{12} \text { : on time delivery rate } \\
\mathrm{U}_{13} \text { : communicate ability } \\
\mathrm{U}_{14} \text { : customer satisfaction } \\
\mathrm{U}_{15} \text { :order tracking ability } \\
\mathrm{U}_{16} \text { :flexible delivery } \\
\mathrm{U}_{17} \text { : cargo damage rate }\end{array}$ \\
\hline & $\begin{array}{l}\text { Service cost } \\
\text { performance indicators } U_{2}\end{array}$ & $\begin{array}{l}\mathrm{U}_{21} \text { : logistics cost control level } \\
\mathrm{U}_{22} \text { : per unit product service cost } \\
\mathrm{U}_{23} \text { : system cost }\end{array}$ \\
\hline & $\begin{array}{l}\text { Market ability } \\
\text { performance indicators } U_{3}\end{array}$ & $\begin{array}{l}\mathrm{U}_{31}: \text { market share } \\
\mathrm{U}_{32}: \text { the market growth rate } \\
\mathrm{U}_{33}: \text { the market strain capacity }\end{array}$ \\
\hline & $\begin{array}{l}\text { Information ability } \\
\text { performance indicators } U_{4}\end{array}$ & $\begin{array}{l}\mathrm{U}_{41} \text { : logistics management informationization level } \\
\mathrm{U}_{42} \text { : information transmission efficiency levels } \\
\mathrm{U}_{43} \text { : infrastructure level }\end{array}$ \\
\hline
\end{tabular}

Table 1. Transport performance evaluation index system of logistics enterprise 


\subsubsection{Service quality}

Transportation security, timeliness, convenience, accuracy and timeliness are important aspects of service level evaluation several. We preliminarily determine the seven indicators to measure the service quality (Guan, 2011).

\subsubsection{Service cost}

Service cost of per unit product: this indicator can be used to evaluate the efficiency of transportation operations and the level of comprehensive management, generally with the ratio of the total freight amount and in the same period quantity of the goods. Transportation costs mainly include all kinds of fuel, parts, road tolls, worker wages, repair, depreciation and other costs.

System cost: as well as various types of transportation cost, we also need to consider related costs of the system, such as storage costs, such as some straight to send cost is very high, but not necessarily more than the costs at a local inventory.

Logistics cost control level: logistics cost control is a central part of the logistics cost management, the control ability to directly determine high and low of logistics cost, which directly affects the economic benefits of enterprises.

\subsubsection{Market ability}

The market ability mainly includes the market share and market growth rate, the market strain capacity, etc (Chen, Cheng \& Chen, 2007).

\subsubsection{Information ability}

Information ability is the important guarantee of sustainable development for transportation in logistics enterprises:

Infrastructure level belongs to the hard technology, mainly includes the transportation hub, logistics parks, logistics technology and equipment, such as the modern three-dimensional automated warehouse facilities investment and use.

Logistics management informationization level: logistics management information technology directly decide the development of the logistics information, logistics information technology is the key to improve the level of logistics management. With the rapid development of science and technology, the modern logistics information technology, such as various kinds of bar code technology, automatic identification technology, automatic sorting technology, satellite positioning technology has become an important tool of logistics operation and the main characteristics of logistics management informationization development. 
Information transmission efficiency: the smooth of information channels, the timeliness and accuracy of delivery is the key to guarantee information exchange. Logistics information transmission inefficient lead to the lack of transparency of inventory, loading and unloading, and transportation, causing the distribution and transportation costs increase (Qu \& Wang, 2012).

\subsection{Determining the evaluation indexes weights $A$}

Each element of evaluation index collection $U$ has different importance in the assessment, therefore according to its important extent, each element must be confirmed different weight number. The weight set $A$ which is composed by each weight number is the fuzzy subsets of evaluation index set $\mathrm{U}$. On the basis of the hierarchical structure model, AHP is used to calculate the weights. The basic procedure is as follows: According to the established hierarchical structure model, in each layer by comparison between two elements, comparative judgment matrix is constructed. Solving features root of judgment matrix $M$, characteristic vector is sorting weights of relative weights of each factor in the same level relative some factor of its upper layer. Then consistency test of the judge matrix is proceeding, until it has satisfactory consistency. Specific procedure is as follows:

\subsubsection{Construct judgment matrix}

The construction of judgment matrix reflects that according to the upper evaluation index $X$, the lower index $Y_{i}$ and $Y_{j}$ construct the relative important degree pairwise comparison matrix $L=\left(L_{i j}\right)_{n \times n}, L_{i j}$ means aimed at the upper evaluation index $X$, the important degree value of $Y_{i}$ compared with $Y_{j}$. Common scale types of construct judgment matrix have 1-9 scale and e0/5 - e8/5 scale. Considering the research question based on single criterion, this paper selects 1-9 scale.

\subsubsection{Calculate weight $A$}

In theory, the weight calculation problem can be attributed to the calculation of the biggest feature root and the eigenvector of judgment matrix. Square Root method, characteristic root method, the least squares method is widely used, among which Square Root method is a simple and feasible method. The Square Root method can be used in the condition of low accuracy requirement, so the paper chooses it.

\subsubsection{Judgment matrix consistency inspection}

The establishment of judgment matrix, makes the judgment thinking mathematical, simplifies the analysis about question, but judgment matrix can not always maintain the consistency of the critical thinking. Namely presumption the importance of the judge index, there were no consistent situation among the judgment. Therefore, it is necessary for judgment matrix to 
carry out the consistency inspection. Random consistency ratio index C.R. can be used to inspect the judgment matrix consistency.

$$
\begin{gathered}
C . R .=\frac{C . I .}{R . I .} \\
C . I .=\frac{\lambda_{\max }-n}{n-1}
\end{gathered}
$$

In the formulas, $\lambda_{\max }$ is the biggest characteristic root for judgment matrix; R.I. is the average random consistency index, Values of R.I. can be seen from table 2.

\begin{tabular}{|c|c|c|c|c|c|c|c|c|c|}
\hline Order & $\mathbf{1}$ & $\mathbf{2}$ & $\mathbf{3}$ & $\mathbf{4}$ & $\mathbf{5}$ & $\mathbf{6}$ & $\mathbf{7}$ & $\mathbf{8}$ & $\mathbf{9}$ \\
\hline RI & 0 & 0 & 0.58 & 0.90 & 1.12 & 1.24 & 1.32 & 1.41 & 1.45 \\
\hline
\end{tabular}

R.I. is the average random consistency index. When C.R. $<0.1$, it's considered good consistency, the judgment matrix can be accepted.

Table 2. Values of R.I.

\subsection{Construct membership function, establish fuzzy judgment matrix $R$}

The role of membership function is that gain the index value then fuzzy them in the field of evaluation grades, make sure the level of each index. Membership functions have various forms. We should choose them based on the characteristics of the rating index or statistics and by expert experience. This paper selects membership functions just as follows:

$$
r_{i j}=\frac{C_{j}}{\sum_{j=1}^{n} C_{j}}
$$

In the above formula, $C_{j}$ as evaluation indexes was appraised $V_{j}$ the number of experts. In index collection $U$, membership degree of NO.i index $U_{i}$ relative to evaluation sets $V$ NO.j element $V_{j}$ is $r_{i j}$, then we can gain the fuzzy judgment matrix $R$.

$$
R=\left[\begin{array}{cccc}
r_{11} & r_{12} & \cdots & r_{1 m} \\
r_{21} & r_{22} & \cdots & r_{2 m} \\
\vdots & \vdots & \ddots & \vdots \\
r_{n 1} & r_{n 2} & \cdots & r_{n m}
\end{array}\right]
$$

\subsection{Fuzzy comprehensive evaluation}

According to the AHP method and multi-level comprehensive evaluation process is from lower of the hierarchical structure model to the top. Through determined a certain level evaluation index weight $A$ and fuzzy judgment matrix $R$, we can obtain the fuzzy evaluation vector $B$, namely

$$
\boldsymbol{B}=\boldsymbol{A} \cdot \boldsymbol{R}=\left(\boldsymbol{a}_{1}, \boldsymbol{a}_{2}, \cdots, \boldsymbol{a}_{\boldsymbol{n}}\right)\left[\begin{array}{cccc}
\boldsymbol{r}_{11} & \boldsymbol{r}_{12} & \cdots & \boldsymbol{r}_{1 m} \\
\boldsymbol{r}_{21} & \boldsymbol{r}_{22} & \cdots & \boldsymbol{r}_{2 m} \\
\vdots & \vdots & \ddots & \vdots \\
\boldsymbol{r}_{\boldsymbol{n} 1} & \boldsymbol{r}_{n 2} & \cdots & \boldsymbol{r}_{n m}
\end{array}\right]=\left(\boldsymbol{b}_{1}, \boldsymbol{b}_{2}, \cdots, \boldsymbol{b}_{\boldsymbol{m}}\right)
$$


In the above formula, $B_{j}$ is fuzzy comprehensive evaluation index, which means under the comprehensive consideration the all factors affecting circumstance, fuzzy comprehensive evaluation vector $B$ is fuzzy subsets of evaluation sets $V$.

\subsection{Comprehensive evaluation result processing, determine the rating}

Through reverse fuzzed the evaluation results $b_{j}$, final evaluation results can be gained. Reverse fuzzed there are many methods, this paper selects the weighted average method.

According to the characteristics of the problem, weighted vector $\gamma$ can be determined which is corresponding evaluation sets level. Industry cluster group competitiveness evaluation are rated \{absolute high, very high, higher, slightly high, generally high\}, the corresponding weighted vector can be set as $\gamma=(0.95,0.85,0.75,0.65,0.55)$. Combining the fuzzy comprehensive evaluation vector $B$, we can get the comprehensive evaluation value $Z$.

$$
Z=\gamma \cdot B^{T}
$$

Comparing the comprehensive evaluation value and the comprehensive evaluation criteria in advance, we can determine The transport performance evaluation of logistics enterprise level.

\section{The transport performance evaluation index system analysis of logistics enterprise}

\subsection{Establish evaluation sets $\mathbf{V}$ and effect assessment index collection $U$}

Evaluation sets $\mathrm{V}$ and effect assessment index collection $\mathrm{U}$ are just as mentioned above.

\subsection{Determining the evaluation indexes weights $A$}

Through the investigation and study, and ask for many experts, according to 1-9 scale, the judgment matrix of $U_{1}-U_{4}$ are respectively determined, the corresponding weight are calculated, and the consistency inspection are carried out. By calculating, we get the results C.R. $<0.1$ which show the consistency of the judgment matrix is acceptable.

For example, the judgment matrix of $U_{1}$ (internal operation performance indicators) just as table 3.

\begin{tabular}{|c|c|c|c|c|c|c|c|}
\hline $\mathbf{U}_{1}$ & $\mathbf{U}_{11}$ & $\mathbf{U}_{12}$ & $\mathbf{U}_{13}$ & $\mathbf{U}_{14}$ & $\mathbf{U}_{15}$ & $\mathbf{U}_{16}$ & $\mathbf{U}_{17}$ \\
\hline$U_{11}$ & 1 & $1 / 8$ & $1 / 7$ & $1 / 6$ & $1 / 2$ & $1 / 3$ & 3 \\
\hline$U_{12}$ & 8 & 1 & 3 & 4 & 6 & 5 & 8 \\
\hline$U_{13}$ & 7 & $1 / 3$ & 1 & 3 & 5 & 4 & 7 \\
\hline$U_{14}$ & 6 & $1 / 4$ & $1 / 3$ & 1 & 3 & 2 & 5 \\
\hline$U_{15}$ & 2 & $1 / 6$ & $1 / 5$ & $1 / 3$ & 1 & $1 / 4$ & 2 \\
\hline$U_{16}$ & 3 & $1 / 5$ & $1 / 4$ & $1 / 2$ & 4 & 1 & 3 \\
\hline$U_{17}$ & $1 / 3$ & $1 / 8$ & $1 / 7$ & $1 / 5$ & $1 / 2$ & $1 / 3$ & 1 \\
\hline
\end{tabular}

$\Lambda_{\max }=7.6577$, C.R. $=0.0806<0.1$

Table 3. The judgment matrix of internal operation performance indicators 
We will get:

$A_{1}=(0.0377,0.4017,0.2558,0.1408,0.0503,0.0805,0.0331)$

Similarly, the rest evaluation index weight of the second can be get:

$A_{2}=(0.7854,0.1488,0.0658)$

$A_{3}=(0.7258,0.1721,0.1020)$

$A_{4}=(0.5396,0.2970,0.1634)$

The first layer evaluation index weight just as follows:

$A=(0.0943,0.3291,0.1096,0.4670)$

\subsection{Establish fuzzy judgment matrix $R$, determine the safety level}

According to the foregoing fuzzy membership functions, every evaluation index belongs to the membership of each evaluation grades is separately calculated, then the corresponding fuzzy judgment matrix $R$ can be get.

For example (with other slightly), the fuzzy judgment matrix of U1 is as follows:

$$
\mathrm{R}_{1}=\left[\begin{array}{ccccc}
0.16 & 0.08 & 0.60 & 0.12 & 0.04 \\
0.80 & 0.08 & 0.12 & 0 & 0 \\
0.12 & 0.72 & 0 & 0.12 & 0.04 \\
0.56 & 0.04 & 0.16 & 0.16 & 0.08 \\
0.08 & 0.24 & 0.60 & 0.04 & 0.04 \\
0.24 & 0.24 & 0.48 & 0.04 & 0 \\
0.12 & 0.24 & 0.24 & 0.24 & 0.16
\end{array}\right]
$$

Then the results can be obtained:

$B_{1}=A_{1} \cdot R_{1}=(0.4643,0.2643,0.1701,0.7092,0.3031)$

Similarly, we can get the follows results:

$B_{2}=A_{2} \cdot R_{2}=(0.8495,0.1307,0.1980,0,0)$

$B_{3}=A_{3} \cdot R_{3}=(0.7346,0.1603,0.1049,0,0)$

$B_{4}=A_{4} \cdot R_{4}=(0.6640,0.3111,0.0250,0,0)$ 
Then the fuzzy relation matrix of comprehensive evaluation is as follows:

$$
R=\left[\begin{array}{ccccc}
0.4643 & 0.2643 & 0.1701 & 0.7092 & 0.3031 \\
0.8495 & 0.1307 & 0.1980 & 0 & 0 \\
0.7346 & 0.1603 & 0.1049 & 0 & 0 \\
0.6640 & 0.3111 & 0.0250 & 0 & 0
\end{array}\right]
$$

Fuzzy comprehensive evaluation vector is as follows:

$B=A \cdot R=(0.7140,0.2308,0.1044,0.6688,0.2858)$

$B$ indicates the overall evaluation results of performance evaluation indicator set $U$ belonging to the membership of each evaluation grade.

By the weighted average principle, safe level can be expressed with a single integrated value.

Logistics enterprise transport performance evaluation index system are rated "absolute high, very high, higher, slightly high, generally high", the corresponding weighted vector $\gamma=(0.95$, $0.85,0.75,0.65,0.55)$. The corresponding comprehensive evaluation which determined by the expert group are just as follows: $[1,0.95],(0.95,0.85],(0.85,0.75],(0.75,0.65],(0.65$, $0.55],(0.65,0]$.

Evaluation vector $B$ is normalized before the Calculation of comprehensive value, the results are as follows:

$\mathrm{B}_{1}{ }^{\prime}=(0.2430,0.1383,0.0890,0.3711,0.1586)$

$\mathrm{B}_{2}{ }^{\prime}=(0.7210,0.1109,0.1681,0,0)$

$\mathrm{B}_{3}{ }^{\prime}=(0.7347,0.1604,0.1049,0,0)$

$B_{4}{ }^{\prime}=(0.6640,0.3110,0.0250,0,0)$

$B^{\prime}=(0.3563,0.1152,0.0521,0.3338,0.1426)$

According the formula (6), we can get the results:

$Z_{1}=0.743, Z_{2}=0.905, Z_{3}=0.913, Z_{4}=0.914, Z=0.771$

According to the comprehensive evaluation criterion, we can get the results:

$Z_{1} \in(0.75,0.65], Z_{2}, Z_{3}, Z_{4} \in(0.95,0.85]$, so there are three evaluation indexes of transport performance evaluation index system of logistics enterprise are in "relatively high" state, and there is one index is in "slightly high" state; 
$Z=0.771 \in(0.85,0.75]$, so, the transport performance evaluation index system of logistics enterprise is in "higher" state.

\section{Conclusions}

Through the above model analysis, we know that the choice of logistics enterprises transportation performance evaluation index system is in the condition of relatively high, which has certain guiding significance to improve transport efficiency and reduce transportation cost for the logistics enterprise. Specifically, the logistics enterprise can do some thing to improve the situation, just as the following aspects: (1) Improve the delivery on-time rate: safe inventory capital takes up huge numbers for logistics enterprises, so many companies now begin to introduce JIT management thoughts, namely "in the most need to be in place in the most timely manner", make inventory capital to minimum. (2) Improve the logistics cost control level: in today's society customer requirements differ in thousands ways, the logistics cost appears positive direction change as the change of the logistics service level, also the absolute logistics cost must have the rising trend. But for logistics enterprises logistics cost control is not helpless, it can change along with the market situation, competitors, product characteristics and seasonal change. Like gloves products for construction enterprise, has a common, price fluctuation is small, the dosage consumption is stable, low-value and easy procurement, can be long-term preservation. Using the total orders to integrate the resources can greatly reduce logistics costs. (3) Keep and increase market share: market share becoming higher shows the stronger competition ability of the enterprise operation and management. Enterprise market share continuously extend, can make the enterprise to obtain some form of monopoly which will lead to monopoly profits as well as keep competitive advantage. (4) Improve the level of logistics management informatization: modern logistics is regarded as "the third profit source" in the economic developing, logistics management informatization is the soul of the modern logistics. The realization of logistics management informatization is the guarantee of improving logistics enterprises profit margin. In a word, higher requirements are put forward in the time for modern logistics informatization, automation, network, intelligent, flexibility. The key objective of modern logistics services in the whole logistics process with the minimum comprehensive cost to meet the needs of customers. Modern logistics enterprises should strictly follow this goal, according to their own advantages and policy guidance to build a safe and efficient circulation chain.

\section{Acknowledgment}

The research work was sponsored by "the humanities and social science research department of Education Department of Hebei Province", project number is SQ131034. 


\section{References}

Chen, Z.Y., Cheng, Q.B., \& Chen, W.Y. (2007). Study on Balanced Scorecard and Analytic Hierarchy Process's Application to Distribution in Our Country. Logistics Sci-Tech, 1, 70-74.

Guan, X. (2011). Performance Evaluation for Coal Logistics Transportation Network. Logistics Technology, 8, 36-38.

Li, Q., Wang, Z., \& Han X. (2009). Based on factor analysis of the performance evaluation of road transportation research. Highway traffic technology, 2, 146-149.

Nie, X., Zhang, Y., \& Yang, D. (2005). A Risk Assessment Method Based on AHP and Fuzzy Theory. Journal of Beijing Electronic Science and Technology Institute, the second issue, 2, 44-49.

Qu, Q., \& Wang, M. (2012). On Constructing the Low Carbon Supply China Management Performance Evaluation Model. China Business and Market, 3, 39-44.

Wei, R. (2006). Index system of transportation performance evaluation and its construction. Logistics technology, 4, 59-61.

Yuan, T., \& Meng, Y. (2013). Demonstration analysis for the low-carbon factors index system of logistics enterprises. Journal of Industrial Engineering and Management, 1, 297-307.

Zhang, Z. (2007). Analysis of logistics transportation outsourcing contracts and performance evaluation. Communications Science and Technology Heilongjiang, 1, 103-105.

Journal of Industrial Engineering and Management, 2013 (www.jiem.org)

Article's contents are provided on a Attribution-Non Commercial 3.0 Creative commons license. Readers are allowed to copy, distribute and communicate article's contents, provided the author's and Journal of Industrial Engineering and Management's names are included. It must not be used for commercial purposes. To see the complete license contents, please visit http://creativecommons.org/licenses/by-nc/3.0/.
} 